\section{Acknowledgement}

This project is supported by the grant from the University of Malaya, Malaysia [H-20001-00-E000058]. Correction added on 7 March 2015 after first online publication: Acknowledgement section was added.

\section{Author contributions}

Dr Mohanarasan Ratanam: wrote the paper. Professor Dr Visvaraja Subrayan: wrote up the case and proof read the manuscript. You Siang Ngim: contributed information from literature search. Assc. Prof. Nurliza Khalidin: performed literature research and proof read the manuscript.

\author{
Mohanarasan Ratanam ${ }^{1}$ \\ You Siang Ngim ${ }^{2}$ \\ Nurliza Khalidin ${ }^{1}$ \\ Visvaraja Subrayan ${ }^{1}$ \\ ${ }^{1}$ Department of Ophthalmology, University of Malaya Medical Centre, \\ Jalan University, Kuala Lumpur, and ${ }^{2}$ Department of Ophthalmology, \\ Sultanah Fatimah Hospital, Muar, Johor, Malaysia. \\ E-mail: mohanslayer@gmail.com
}

Keywords: Waldenström macroglobulinaemia, venous thrombosis, vascular endothelial growth factors, plasma exchange, B Cells

First published online 30 January 2015

doi: $10.1111 /$ bjh.13307

\author{
References \\ Alexander, P., Flanagan, D., Rege, K., Foss, A. \& \\ Hingorani, M. (2008) Bilateral simultaneous \\ central retinal vein occlusion secondary to hy- \\ perviscosity in Waldenstrom's macroglobulinae- \\ mia. Eye London Journal, 22, 1089-1092. \\ Baker, P.S., Garg, S.J., Fineman, M.S., Chiang, A., \\ Alshareef, R.A., Belmont, J. \& Brown, G.C. \\ (2013) Serous macular detachment in Walden- \\ strom macroglobulinemia: a report of four cases. \\ American journal of ophthalmology, 155, 448- \\ 455. \\ Besirli, C.G. \& Johnson, M.W. (2013) Immuno- \\ gammopathy maculopathy associated with Wal- \\ denstrom macroglobulinemia is refractory to \\ conventional interventions for macular edema. \\ Retinal Cases \& Brief Reports, 7, 319-324.
}

Buske, C., Leblond, V., Dimopoulos, M., Kimby, E., Jager, U., Dreyling, M. \& for the ESMO Guidelines Working Group (2013) Waldenstrom's macroglobulinaemia: ESMO Clinical Practice Guidelines for diagnosis, treatment and followup. Annals of oncology, 24(Suppl. 6), vi155-9.

Caimi, A., Giani, A., Bottoni, F. \& Staurenghi, G. (2013) Serous macular detachment in Waldenstrom macroglobulinemia: a report of 4 cases. American journal of ophthalmology, 155, 955-956. Fenicia, V., Balestrieri, M., Perdicchi, A., Maraone, G. \& Recupero, S.M. (2013) Intravitreal injection of dexamethasone implant in serous macular detachment associated with Waldenstrom's disease. Case Reports in Ophthalmology, 4, 64-69.

Hyun, J.S., Ki, C.S., Hyewon, C. Hyung, C.K. (2014) Change of retinal nerve fiber layer thickness in various retinal diseases treated with multiple intravitreal antivascular endothelial growth factor. Investigative Ophthalmology and Visual Science, 55, 2403-2411.

Owen, R.G., Treon, S.P., Al-Katib, A., Fonseca, R., Greipp, P.R., McMaster, M.L., Morra, E., Pangalis, G.A., San Miguel, J.F., Branagan, A.R. \& Dimopoulos, M.A. (2003) Clinicopathological definition of Waldenström's macroglobulinemia: consensus panel recommendations from the Second International Workshop on Waldenström's Macroglobulinemia. Seminars in Oncology, 30, 110-115.

Subrayan, V., Khaw, K.W., Peyman, M., Koay, A.C. \& Tajunisah, I. (2013) Intravitreal bevacizumab for radiation-induced cyctoid macular oedema in patients with nasopharyngeal carcinoma: a clinical series. Ophthalmologica, 229, 208-211.

\title{
Risk of invasive fungal infection in patients affected by acute promyelocytic leukaemia. A report by the SEIFEM-D registry
}

Patients with acute promyelocytic leukaemia (APL) are usually considered at lower risk for developing an infectious complication (Girmenia et al, 2003), principally because current treatments are mainly based on the induction of myeloid differentiation rather than the highly myeloablative properties of standard chemotherapy used in patients with acute myeloid leukaemia (AML).

This prospective study, conducted in 33 locations throughout Italy, evaluated the incidence of invasive fungal infection (IFI) and the clinical characteristics in patients with APL compared to patients affected by other AML subtypes treated with intensive chemotherapy. Consecutive adult patients with newly diagnosed AML $(n=1192)$ were enrolled in the study between 1 January, 2010 and 30 April, 2012: 1086 had non promyelocytic-AML (npAML) and 106 had APL.

Only 881 of the 1086 npAML patients received intensive chemotherapy and were considered evaluable. Two-hundred and fourteen cases of IFIs were recorded (24\%) after the induction phase, with 23 yeast infections (3\%) and 191 moulds $(22 \%)$. The majority of moulds were possible (136, $71 \%)$, while the remaining 55 cases were probable $(n=48)$ or proven $(n=7)$ IFIs (Table I). Three of the 106 APL patients were excluded from the analysis (one early haemorrhagic death and two poor performance status). Among the remaining 103 patients, 90 were treated with all trans retinoic 
acid (ATRA) plus chemotherapy including idarubicin and 13 received ATRA plus arsenic trioxide (ATO).

Overall, 10 APL patients (9.7\%) had an IFI: eight in induction phase, one in consolidation and one at time of relapse. All eight patients $(7 \cdot 7 \%)$ who developed an IFI after induction treatment (one proven, three probable and four possible) had a mould infection. All IFIs were observed in patients treated with ATRA plus chemotherapy. Overall, eight APL patients died during the induction phase (one IFI, four cerebral haemorrhage and three bacterial sepsis). A total of 95 patients (92\%) achieved a complete remission (CR). All APL patients were further followed for a median duration of 36 months (range 3-54) and only two more cases of IFI have been observed: one possible mould infection during consolidation (mitoxantrone, etoposide and ATRA) at 16 weeks from APL diagnosis, and one probable case in a patient with relapsed APL at 132 weeks. Notably, six of the 95 patients $(6 \%)$ who achieved CR subsequently relapsed. Among these patients, only four received a second induction treatment, two with ATO + ATRA and two with standard AML-like chemotherapy. One probable pulmonary aspergillosis was reported in a patient who had received a fludarabine-based chemotherapy (Table II). Only one patient died of cerebral aspergillosis during first induction, while the remaining seven patients were successfully treated with antifungal therapy. The patient who developed IFI during consolidation recovered from infection.

During the follow-up, five additional patients died of septicaemia $(n=1)$, cardiac failure $(n=1)$ and haemorrhage $(n=3)$.

Although not completely comparable, the npAML and APL cohorts were evaluated in order to analyse the main differences between the two groups within $90 \mathrm{~d}$ of starting their

Table I. Main characteristics of APL and AML patients treated with curative chemotherapy and comparison of these two groups of patients for IFI risk during first induction chemotherapy.

\begin{tabular}{|c|c|c|c|}
\hline & APL (cases) & AML (cases) & $P$-value ${ }^{*}$ \\
\hline Patients $(n)$ & 103 & 881 & \\
\hline Age, years, median (IQR) & $50(40-64)$ & $58(47-66)$ & 0.01 \\
\hline Male/Female & $50 / 53$ & $448 / 433$ & $0 \cdot 5$ \\
\hline \multicolumn{4}{|l|}{ Performance status (WHO) } \\
\hline $0-1$ & 76 & 284 & \multirow[t]{2}{*}{$<0.0001$} \\
\hline$>1$ & 27 & 597 & \\
\hline Mucosal barrier disruption & $56(54 \%)$ & $512(58 \%)$ & $0 \cdot 4$ \\
\hline Central venous catheter & $52(50 \%)$ & $687(78 \%)$ & $<0.0001$ \\
\hline Neutropenia $\left(<1\right.$ neutrophils $\left.\times 10^{9} / 1\right)$ & $103(100 \%)$ & $874(99 \%)$ & $0 \cdot 3$ \\
\hline $\begin{array}{l}\text { Duration of neutropenia }<1 \text { neutrophils } \times 10^{9} / 1 \text {, days, } \\
\text { median (IQR) }\end{array}$ & $23 \cdot 5(15-30)$ & $23(18-29)$ & $0 \cdot 45$ \\
\hline $\begin{array}{l}\text { Duration of severe neutropenia }<0.5 \text { neutrophils } \times 10^{9} / \text { l, days, } \\
\text { median (IQR) }\end{array}$ & $18(6-25)$ & $20(15-26)$ & 0.003 \\
\hline Antifungal prophylaxis & $94(91 \%)$ & $837(95 \%)$ & $0 \cdot 1$ \\
\hline Topical antifungal prophylaxis only & $17(17 \%)$ & $60(7 \%)$ & 0.0005 \\
\hline \multicolumn{4}{|l|}{ Prophylactic used } \\
\hline Fluconazole & $33(32 \%)$ & $168(19 \%)$ & 0.002 \\
\hline Itraconazole & $13(12 \%)$ & $117(13 \%)$ & $0 \cdot 8$ \\
\hline Posaconazole & $38(37 \%)$ & $513(58 \%)$ & $<0.0001$ \\
\hline Other & $1(1 \%)$ & $23(3 \%)$ & \\
\hline \multicolumn{4}{|l|}{ IFI } \\
\hline All cases & $8(7 \%)$ & $214(24 \%)$ & 0.0001 \\
\hline Proven/probable & $4(4 \%)$ & $77(9 \%)$ & $0 \cdot 08$ \\
\hline \multicolumn{4}{|l|}{ Moulds } \\
\hline All cases & $8(7 \%)$ & $191(22 \%)$ & 0.0006 \\
\hline Proven/probable & $4(4 \%)$ & $55(6 \%)$ & $0 \cdot 4$ \\
\hline \multicolumn{4}{|l|}{ Yeasts } \\
\hline All cases & 0 & $23(3 \%)$ & $<0.0001$ \\
\hline Antifungal treatment & $11(11 \%)$ & $275(31 \%)$ & $<0.0001$ \\
\hline Duration of treatment, days, median (IQR) & $14(7-30)$ & $12(8-16)$ & $0 \cdot 6$ \\
\hline Overall mortality at $30 \mathrm{~d}$ & $8(8 \%)$ & $110(12 \%)$ & $0 \cdot 1$ \\
\hline Mortality due to IFI at $30 \mathrm{~d}$ & $1(1 \%)$ & $25(3 \%)$ & 0.5 \\
\hline
\end{tabular}

APL, acute promyelocytic leukaemia; AML, acute myeloid leukaemia; IQR, interquartile range; WHO, World Health Organization; IFI, invasive fungal infection.

${ }^{*}$ The Wilcoxon rank sum test was used to compare continuous variables. Categorical variables were evaluated with the $\chi^{2}$ or two-tailed Fisher's exact test. 


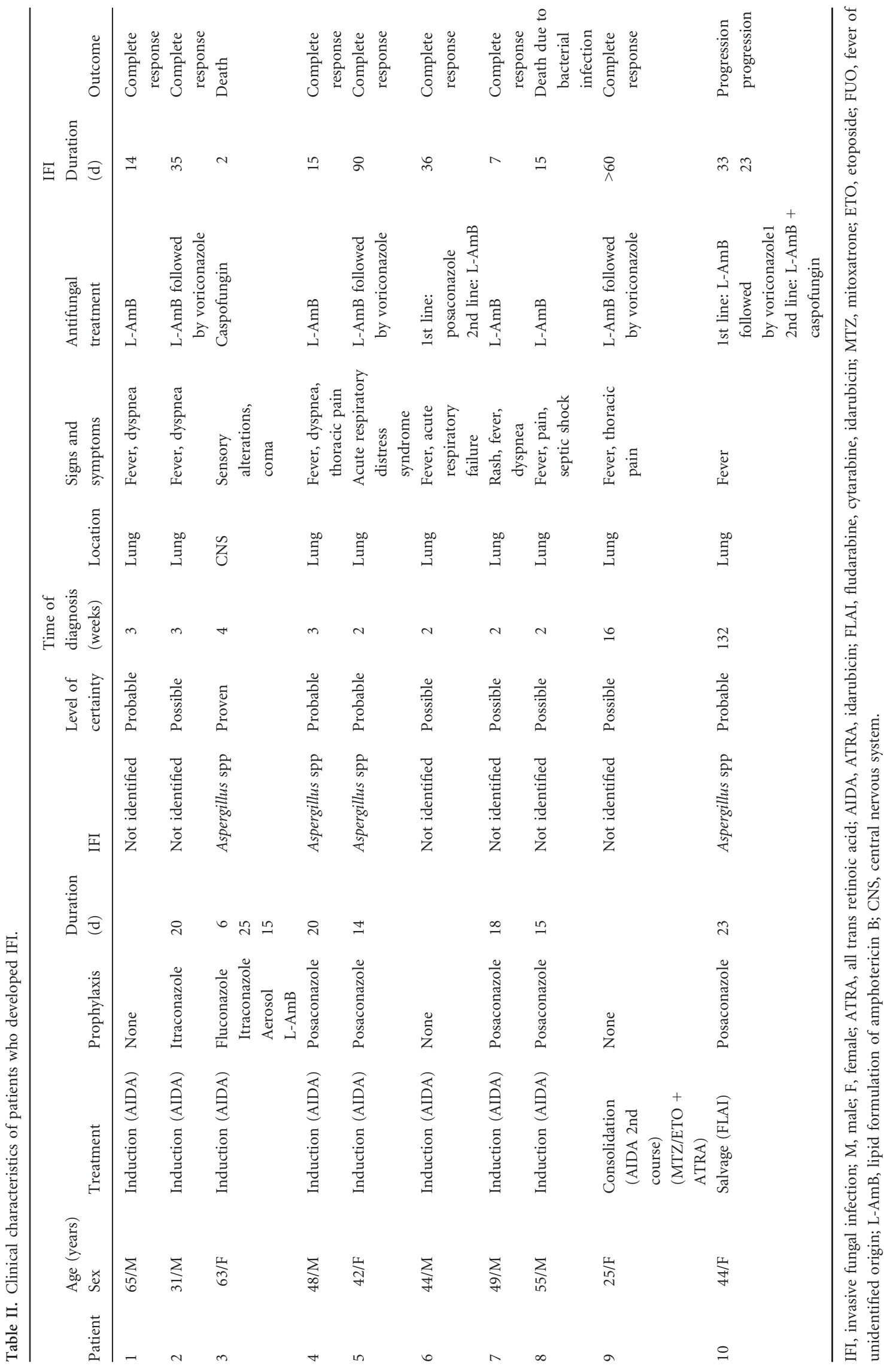


first treatment for leukaemia (Table I). Significant differences were observed regarding the prophylactic drug used: posaconazole was more frequently applied in npAML. Although the prophylaxis was less mould-oriented in APL, the overall incidence of IFI and the incidence of mould infections were both markedly higher in npAML. A significant difference was observed between APL and npAML with regard to systemic antifungal treatment, as it was more frequently utilized in npAML. Interestingly, while the number of patients who developed neutropenia was similar in the two groups, the median duration of severe neutropenia $(<0.5$ neutrophils $\left.\times 10^{9} / \mathrm{l}\right)$ was significantly shorter in the APL arm. No significant difference regarding overall mortality and attributable mortality among the two patient cohorts was recorded. No significant factors associated with the onset of an IFI among APL were identified.

Before the advent of ATRA, patients were treated with chemotherapy alone, which yielded CR rates of $50-80 \%$. However, deaths were often caused by infections owing to the use of chemotherapy regimens similar to those administered to npAML patients, leading to prolonged severe neutropenia (Cordonnier et al, 1985; Tallman et al, 1997). The inclusion of ATRA in combination with chemotherapy and subsequently that of ATO definitely improved patient outcomes thus turning APL into a highly curable disease. Meanwhile, the use of these agents enabled a decrease/deescalation of the chemotherapeutic agents used. The reduction of the chemotherapeutic 'burden' also reduced chemotherapy-related toxicity; in particular, the reduced duration of severe neutropenia observed may, in turn, affect morbidity and mortality from infectious complications. However the risk of infection is not completely absent, especially if high dose cytarabine is included in the consolidation regimen (Lo-Coco et al, 2010; Sanz et al, 2010; Iland et al, 2012).

Few IFIs in APL have been reported in clinical trials (de la Serna et al, 2008; Iland et al, 2012), and only four cases $(4 \cdot 5 \%)$ of non-fatal IFI were reported (one pulmonary mycetoma, two hepatosplenic candidiasis and one candidaemia) in a series of 89 APL patients treated with the AIDA protocol (ATRA + idarubicin) (Girmenia et al, 2003), while in a paediatric series of $33 \mathrm{APL}$, only two patients (6.1\%) experienced fungal infection (Cellot et al, 2013).

Similar to the results reported in npAML patients (Pagano et al, 2006), the majority of APL cases in the present study developed IFI after first induction treatment. All IFIs occurred in patients treated with ATRA plus chemotherapy. Only a few patients relapsed and it is noteworthy that one of the two patients treated with an aggressive second line induction therapy developed an IFI. This suggests that if the patients had received an aggressive chemotherapy, characterized by a prolonged neutropenia, the risk of IFI would probably have been similar to that of npAML.

Overall, the rate of IFI was significantly lower among patients with APL compared to those with npAML. Unlike the npAML cohort, posaconazole was significantly less utilized in
APL patients. Another interesting observation is the total absence of yeast infections in the APL group in our series.

On the basis of this study, APL patients must be considered at lower risk of IFI if treated with differentiation-inducing agents. Taking the substantial cost of prophylactic antifungal treatment and the possible side effects, interaction between azoles and drugs active for the treatment of APL (Naito et al, 2006) into account, a mould active antifungal prophylaxis could be omitted in APL patients at the first induction phase of their treatment.

\section{Acknowledgement}

This paper was supported by a grant from Fondi Ateneo UCSC 2013.

\section{Author contributions}

LP and FA designed the study and wrote the paper. MT, MC and MS analysed the data and wrote the paper. $\mathrm{AB}, \mathrm{AN}, \mathrm{CC}$ and $\mathrm{AC}$ participated in the data collection and revision of the paper. All the other authors collected the data. All the authors approved the submitted final version.

\section{Disclosures}

L.P. has received honoraria from Gilead Sciences, ScheringPlough, Astellas Pharma, Merck and Pfizer Pharmaceuticals. M.C. has received honoraria from Gilead Sciences, Merck, Pfizer Pharmaceuticals and Schering-Plough. F.A. has received honoraria from Gilead Sciences, Schering-Plough-Merck and Pfizer Pharmaceuticals and has been a speaker for Gilead Sciences, Schering-Plough-Merck, Pfizer Pharmaceuticals and Cephalon. M.T. has received honoraria from Gilead Sciences and Merck. A.N. has received honoraria from Gilead Sciences and Merck. A.B. has received honoraria from Gilead Sciences and Merck.

All other authors report no potential conflicts.

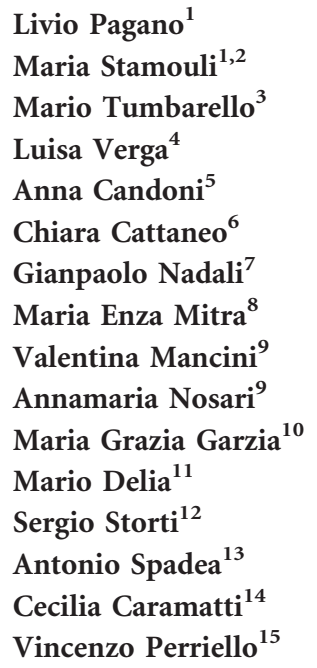




\begin{tabular}{|c|c|}
\hline Marco Sanna ${ }^{16}$ & da, Milan, ${ }^{10}$ Divisione di Ematologia, Ospedale San Camillo, Rome, \\
\hline Adriana Vacca ${ }^{16}$ & ${ }^{11}$ Sezione di Ematologia, Università di Bari, Bari, ${ }^{12}$ Divisione di Emat- \\
\hline Maria Rosaria De Paolis ${ }^{17}$ & ologia, Università Cattolica del S. Cuore, Campobasso, ${ }^{13}$ Ematologia, \\
\hline Leonardo Potenza $^{18}$ & Istituti Fisioterapici Ospitalieri, Rome, ${ }^{14}$ Sezione di Ematologia, Univer- \\
\hline Prassede Salutari ${ }^{19}$ & sità di Parma, Parma, ${ }^{15}$ Istituto di Ematologia, Università di Perugia, \\
\hline Carlo Castagnola ${ }^{20}$ & Perugia, ${ }^{16}$ Istituto di Ematologia, Università di Cagliari, Cagliari, \\
\hline Rosa Fanci ${ }^{21}$ & ${ }^{17}$ Dipartimento di Ematologia, Ospedale di Lecce, Lecce, ${ }^{18}$ Sezione di \\
\hline Anna Chierichini ${ }^{22}$ & Ematologia, Dipartimento di Scienze Mediche Materno Infantili e \\
\hline Lorella Melillo $^{23}$ & dell'Adulto, Università degli Studi di Modena e Reggio Emilia, Modena, \\
\hline Marco Picardi ${ }^{24}$ & ${ }^{19}$ Dipartimento di Ematologia Clinica, Ospedale Spirito Santo, Pescara, \\
\hline Luca Facchini $^{25}$ & ${ }^{20}$ Dipartimento Onco-Ematologico, Fondazione IRCCS Policlinico San \\
\hline Bruno Martino ${ }^{26}$ & Matteo, Pavia, ${ }^{21}$ Unità Operativa di Ematologia, Università di Firenze, \\
\hline Roberta Di Blasi $^{1}$ & Firenze, ${ }^{22}$ Divisione di Ematologia, Ospedale S. Giovanni Addolorata, \\
\hline Monica Cesarini ${ }^{1}$ & Rome, ${ }^{23}$ Divisione di Ematologia, IRCCS Casa Sollievo della Sofferenza, \\
\hline Massimo Offidani $^{27}$ & S. Giovanni Rotondo, ${ }^{24}$ Divisione di Ematologia, Università Federico II \\
\hline Nicola Vianelli ${ }^{28}$ & di Napoli, Napoli, ${ }^{25}$ Divisione di Ematologia, Arciospedale S. Maria \\
\hline Morena Caira $^{1}$ & Nuova, Reggio Emilia, ${ }^{26}$ Divisione di Ematologia, Azienda Ospedaliera \\
\hline Federica Lessi ${ }^{29}$ & BMM, Reggio Calabria, ${ }^{27}$ Clinica di Ematologia, Università di Ancona, \\
\hline Antonella Ferrari ${ }^{30}$ & Ancona, ${ }^{28}$ Istituto di Ematologia ed Oncologia Clinica, Ospedale \\
\hline Adriano Venditti ${ }^{31}$ & S. Orsola-Malpighi, Università di Bologna, Bologna, ${ }^{29}$ Ematologia ed \\
\hline Vincenzo Pavone ${ }^{32}$ & Immunologia Clinica, Dipartimento di Medicina, Università di Padova, \\
\hline Francesco Lo-Coco ${ }^{10}$ & Padova, ${ }^{30}$ Divisione di Ematologia, Ospedale S.Andrea,,${ }^{31}$ Istituto di \\
\hline Franco Aversa ${ }^{14}$ & Ematologia, Università di Tor Vergata, Rome,${ }^{32}$ Clinica di Ematologia, \\
\hline Alessandro Busca ${ }^{33}$ & Ospedale di Tricase, Tricase, and ${ }^{33}$ Dipartimento di Ematologia, Ospe- \\
\hline on behalf of the SEIFEM Group (Sorveglianza & dale S.Giovanni Battista, Torino, Italy. \\
\hline Epidemiologica Infezioni Fungine in Emopatie Maligne) & E-mail:lpagano@rm.unicatt.it \\
\hline
\end{tabular}

${ }^{1}$ Istituto di Ematologia, Università Cattolica del Sacro Cuore, Rome, Italy, ${ }^{2}$ 2nd Department of Internal Medicine Propaedeutic, Attikon University Hospital, Athens, Greece, ${ }^{3}$ Istituto di Malattie Infettive, Università Cattolica Del Sacro Duore, Rome, ${ }^{4}$ Unità di Ematologia, Ospedale San Gerardo, Università di Milano, Monza, ${ }^{5}$ Clinica di Ematologia, Università di Udine, Udine, ${ }^{6}$ Divisione di Ematologia, Spedali Civili di Brescia, Brescia, ${ }^{7}$ UOC Ematologia, Azienda Ospedaliera Universitaria Integrata di Verona, Verona, ${ }^{8}$ Divisione di Ematologia e TMO, Policlinico di Palermo, Palermo, ${ }^{9}$ Divisione di Ematologia e Centro Trapianti Midollo, Ospedale Niguarda Ca' Gran-

\begin{abstract}
da, Milan, ${ }^{10}$ Divisione di Ematologia, Ospedale San Camillo, Rome, ${ }^{11}$ Sezione di Ematologia, Università di Bari, Bari, ${ }^{12}$ Divisione di Ematologia, Università Cattolica del S. Cuore, Campobasso, ${ }^{13}$ Ematologia, Istituti Fisioterapici Ospitalieri, Rome, ${ }^{14}$ Sezione di Ematologia, Univer sità di Parma, Parma, ${ }^{15}$ Istituto di Ematologia, Università di Perugia, Perugia, ${ }^{16}$ Istituto di Ematologia, Università di Cagliari, Cagliari, ${ }^{17}$ Dipartimento di Ematologia, Ospedale di Lecce, Lecce, ${ }^{18}$ Sezione di Ematologia, Dipartimento di Scienze Mediche Materno Infantili e dell Adulto, Università degli Studi di Modena e Reggio Emilia, Modena, ${ }^{20}$ Dipartimento Onco-Ematologico, Fondazione IRCCS Policlinico San Matteo, Pavia, ${ }^{21}$ Unità Operativa di Ematologia, Università di Firenze, Rome, ${ }^{23}$ Divisione di Ematologia, IRCCS Casa Sollievo della Sofferenza, S. Giovanni Rotondo, ${ }^{24}$ Divisione di Ematologia, Università Federico II di Napoli, Napoli, ${ }^{25}$ Divisione di Ematologia, Arciospedale S. Maria Nuova, Reggio Emilia, ${ }^{26}$ Divisione di Ematologia, Azienda Ospedaliera BMM, Reggio Calabria, ${ }^{27}$ Clinica di Ematologia, Università di Ancona, Ancona, ${ }^{28}$ Istituto di Ematologia ed Oncologia Clinica, Ospedale Immunologia Clinica, Dipartimento di Medicina, Università di Padova, Padova, ${ }^{30}$ Divisione di Ematologia, Ospedale S.Andrea, , ${ }^{31}$ Istituto di Ospedale di Tricase, Tricase, and ${ }^{33}$ Dipartimento di Ematologia, OspeE-mail:lpagano@rm.unicatt.it
\end{abstract}

\section{Clinicaltrial.gov: NCT01315925}

Keywords: acute promyelocytic leukaemia, aspergillosis, invasive fungal infection

First published online 27 January 2015

doi: 10.1111/bjh.13308

\section{References}

Cellot, S., Johnston, D., Dix, D., Ethier, M.C., Gillmeister, B., Mitchell, D., Yanofsky, R., Lewis, V., Portwine, C., Price, V., Zelcer, S., Silva, M., Bowes, L., Michon, B., Stobart, K., Brossard, J., Beyene, J. \& Sung, L. (2013) Infections in pediatric acute promyelocytic leukaemia: from the canadian infections in acute myeloid leukaemia research group. BMC Cancer, 13, 276.

Cordonnier, C., Vernant, J.P., Brun, B., Heilmann, M.G., Kuentz, M., Bierling, P., Farcet, J.P., Rodet, M., Duedari, N., Imbert, M., Jouault, H., Mannoni, P., Reyes, F., Dreyfus, B. \& Rochant, H. (1985) Acute promyelocytic leukaemia in 57 previously untreated patients. Cancer, 55, 18-25.

Girmenia, C., Lo Coco, F., Breccia, M., Latagliata, R., Spadea, A., D'Andrea, M., Gentile, G., Micozzi, A., Alimena, G., Martino, P. \& Mandelli, F. (2003) Infectious complications in patients with acute promyelocytic leukaemia treated with the AIDA regimen. Leukemia, 17, 925-930.

Iland, H.J., Bradstock, K., Supple, S.G., Catalano, A., Collins, M., Hertzberg, M., Browett, P., Grigg, A., Firkin, F., Hugman, A., Reynolds, J., Di Iulio, J., Tiley, C., Taylor, K., Filshie, R., Seldon, M., Taper, J., Szer, J., Moore, J., Bashford, J., Seymour, J.F. \& Australasian Leukaemia and Lymphoma Group (2012) All-trans-retinoic acid, idarubicin, and IV arsenic trioxide as initial therapy in acute promyelocytic leukaemia (APML4). Blood, 120, 1570-1580.

Lo-Coco, F., Avvisati, G., Vignetti, M., Breccia, M., Gallo, E., Rambaldi, A., Paoloni, F., Fioritoni, G., Ferrara, F., Specchia, G., Cimino, G., Diverio, D., Borlenghi, E., Martinelli, G., Di Raimondo, F., Di Bona, E., Fazi, P., Peta, A., Bosi, A., Carella, A.M., Fabbiano, F., Pogliani, E.M., Petti, M.C., Amadori, S., Mandelli, F. \& Italian GIMEMA Cooperative Group (2010)
Front-line treatment of acute promyelocytic leukaemia with AIDA induction followed by risk-adapted consolidation for adults younger than 61 years: results of the AIDA-2000 trial of the GIMEMA Group. Blood, 116, 31713179 .

Naito, K., Kobayashi, M., Sahara, N., Shigeno, K., Nakamura, S., Shinjo, K., Tobita, T., Takeshita, A., Ohno, R. \& Ohnishi, K. (2006) Two cases of acute promyelocytic leukaemia complicated by torsade de pointes during arsenic trioxide therapy. International Journal of Hematology, 83, 318-323.

Pagano, L., Caira, M., Candoni, A., Offidani, M., Fianchi, L., Martino, B., Pastore, D., Picardi, M., Bonini, A., Chierichini, A., Fanci, R., Caramatti, C., Invernizzi, R., Mattei, D., Mitra, M.E., Melillo, L., Aversa, F., Van Lint, M.T., Falcucci, P., Valentini, C.G., Girmenia, C. \& Nosari, A. (2006) The epidemiology of fungal infections in 
patients with hematologic malignancies: the SEIFEM-2004 study. Haematologica, 91, 1068-1075. Sanz, M.A., Montesinos, P., Rayón, C., Holowiecka, A., de la Serna, J., Milone, G., de Lisa, E., Brunet, S., Rubio, V., Ribera, J.M., Rivas, C., Krsnik, I., Bergua, J., González, J., Díaz-Mediavilla, J., Rojas, R., Manso, F., Ossenkoppele, G., González, J.D., Lowenberg, B. \& PETHEMA and HOVON Groups (2010) Risk-adapted treatment of acute promyelocytic leukaemia based on all- trans retinoic acid and anthracycline with addition of cytarabine in consolidation therapy for high-risk patients: further improvements in treatment outcome. Blood, 115, 5137-5146.

de la Serna, J., Montesinos, P., Vellenga, E., Rayón, C., Parody, R., León, A., Esteve, J., Bergua, J.M., Milone, G., Debén, G., Rivas, C., González, M., Tormo, M., Díaz-Mediavilla, J., González, J.D., Negri, S., Amutio, E., Brunet, S., Lowenberg, B. \& Sanz, M.A. (2008) Causes and prognostic fac- tors of remission induction failure in patient with acute promyelocytic leukaemia treated with all-trans retinoic acid and idarubicin. Blood, 111, 3395-3402.

Tallman, M.S., Andersen, J.W., Schiffer, C.A., Appelbaum, F.R., Feusner, J.H., Ogden, A., Shepherd, L., Willman, C., Bloomfield, C.D., Rowe, J.M. \& Wiernik, P.H. (1997) All-trans-retinoic acid in acute promyelocytic leukaemia. New England Journal of Medicine, 337, 1021-1028. 